\title{
The Real-Life Efficacy And Safety of Osimertinib In Pretreated Advanced Non-Small Cell Lung Cancer Patients With T790M Mutation: A Turkish Oncology Group Study
}

Mutlu Hizal ( $\nabla$ drmutluhizal@hotmail.com )

Ankara City Hospital: Ankara Sehir Hastanesi https://orcid.org/0000-0001-5147-4431

\section{Burak Bilgin}

Ataturk Chest Diseases and Chest Surgery Training and Research Hospital: Ataturk Gogus Hastaliklari ve Gogus Cerrahisi Egitim ve Arastirma Hastanesi

\section{Nail Paksoy}

Istanbul University Istanbul Faculty of Medicine: Istanbul Universitesi Istanbul Tip Fakultesi

\section{Özgür Açıkgöz}

Istanbul Medipol University Faculty of Medicine: Istanbul Medipol Universitesi Tip Fakultesi

\section{Ahmet Sezer}

Baskent University: Baskent Universitesi

\section{Mustafa Gürbüz}

Ankara University Faculty of Medicine: Ankara Universitesi Tip Fakultesi

\section{Naziye Ak}

Yozgat City Hospital

\section{Şebnem Yücel}

Ataturk Chest Diseases and Chest Surgery Training and Research Hospital: Ataturk Gogus Hastaliklari ve Gogus Cerrahisi Egitim ve Arastirma Hastanesi

\section{Murat Ayhan}

Istanbul Dr Lufti Kirdar Kartal Egitim ve Arastirma Hastanesi

\section{Cihan Erol}

Yıldırım Beyazıt Üniversitesi: Ankara Yildirim Beyazit Universitesi

\section{Aykut Demirkıran}

Necmettin Erbakan Universitesi Meram Tip Fakultesi

\section{Nil Molinas Mandel}

Istanbul American Hospital

\section{Abdallah Shbair}

Bezmialem Vakif University: Bezmialem Vakif Universitesi

\section{Ivo Gökmen}

Trakya University Faculty of Medicine: Trakya Universitesi Tip Fakultesi 


\section{Tuğba Başoğlu}

Marmara University: Marmara Universitesi

\section{Semra Paydaş}

Cukurova University Faculty of Medicine: Cukurova Universitesi Tip Fakultesi

\section{Atike Gökçen Demiray}

Pamukkale University School of Medicine: Pamukkale Universitesi Tip Fakultesi

\section{Yakup İriağaç}

Namık Kemal Üniversitesi Tip Fakültesi: Namik Kemal Universitesi Tip Fakultesi

\section{Teoman Şakalar}

Necip Fazıl City Hospital

\section{Esra Zeynelgil}

Ankara Dışkapı Yıldırım Beyazıt Eğitim ve Araştırma Hastanesi: Ankara Diskapi Yildirim Beyazit Egitim ve Arastirma Hastanesi

\section{Ali Murat Tatlı}

Akdeniz University: Akdeniz Universitesi

\section{Aykut Bahçeci}

Dr Ersin Arslan Training and Research Hospital: Dr Ersin Arslan Egitim ve Arastirma Hastanesi

\section{Deniz Can Güven}

Hacettepe Universitesi Tip Fakultesi

\section{Burcu Caner}

Uludag University Faculty of Medicine: Uludag Universitesi Tip Fakultesi

\section{Alper Can}

Istinye University: Istinye Universitesi

\section{Ahmet Gülmez}

İnönü Üniversitesi: Inonu Universitesi

\section{Yusuf Karakaş}

Bodrum Acıbadem Hospital

\section{Bülent Yalçın}

Yıldırım Beyazıt Üniversitesi: Ankara Yildirim Beyazit Universitesi

\section{Ahmet Demirkazık}

Ankara University: Ankara Universitesi

\section{Ahmet Bilici}

Istanbul Medipol University: Istanbul Medipol Universitesi

\section{Adnan Aydıner}

Istanbul University Istanbul Faculty of Medicine: Istanbul Universitesi Istanbul Tip Fakultesi

\section{Perran Fulden Yumuk}

Marmara University: Marmara Universitesi

\section{Mehmet Ali Nahit Şendur}

Yıldırım Beyazıt Üniversitesi: Ankara Yildirim Beyazit Universitesi 


\section{Research Article}

Keywords: Osimertinib, disease, discontinuation, TTD, ORR

Posted Date: May 7th, 2021

DOI: https://doi.org/10.21203/rs.3.rs-486874/v1

License: (c) (i) This work is licensed under a Creative Commons Attribution 4.0 International License. Read Full License

Version of Record: A version of this preprint was published at Journal of Cancer Research and Clinical Oncology on July 31st, 2021. See the published version at https://doi.org/10.1007/s00432-021-03748-7. 


\section{Abstract}

Introduction: Osimertinib, an irreversible third-generation EGFR-TKI, is the standard of care for second-line treatment of T790M-mutant advanced NSCLC patients whose progressed after first-line EGFR-TKI therapy. In this multicenter study, we aimed to determine the real-life efficacy and safety of Osimertinib in pretreated advanced NSCLC patients with T790M mutation.

Materials and Methods: This retrospective trial included advanced T790M-mutant pretreated NSCLC patients who received Osimertinib from 24 different centers in Turkey. Primary endpoint was time-totreatment discontinuation (TTD). Secondary endpoints were objective response rate (ORR), overall survival (OS), and safety.

Results: Of 163 patients $68.7 \%$ had EGFR exon 19 deletion and $22.7 \%$ had exon 21 L858R mutation. Osimertinib was given as second-line treatment in 96 patients (58.9\%) and third-line in 48 patients (29.4\%). After median of 13 months disease follow-up, median TTD was 21.6 months with an $82.2 \%$ ORR. Estimated median OS was 32.1 months. Grade $3-4$ adverse events were seen in $11.7 \%$ of the patients.

Conclusion: Osimertinib is a highly effective option in second or third-line treatment of NSCLC patients with T790M mutation, with a favorable safety profile.

\section{Introduction}

Non-small cell lung cancer (NSCLC) is one of the leading causes of cancer-related morbidity and mortality (1). In the last decade, survival expectancy has dramatically changed for some patient subgroups with the identification of druggable driver mutations which suitable for targeted therapies (2). Activating mutation in the gene which encodes the proteins of the Epidermal growth factor receptor (EGFR) constitutes one of the most important treatment targets, and pooled prevalence of exon 19 and exon 21 mutations in NSCLC patients is reported approximately $32 \%$ by previous studies (3).

Until recently, first-generation EGFR tyrosine kinase inhibitors (TKIs) (Erlotinib, Gefitinib), and secondgeneration TKl, Afatinib were the standard of care options for first-line treatment of advanced NSCLC with EGFR exon 19 deletion and 21 mutations. However, resistance seen in 10-14 months to these TKIs was the most important determinant to limited efficacy in terms of duration of response (DoR) and progression-free survival (PFS) for most of the patients (2). T790M mutation occurs in exon 20 of the EGFR gene, converts ATP-binding pocket of the receptor to a nonpolar, hydrophobic state which interferes with drug-binding and causes a lack of efficacy (4). This point mutation was demonstrated in $60 \%$ of the patients at the time of progression (5).

Osimertinib is an irreversible, third-generation EGFR-TKI which is also effective in patients with T790M mutation (4). AURA3 was a phase 3 trial that randomized 419 patients with T790M-positive advanced NSCLC, who had disease progression after first-line EGFR-TKI therapy (6). This study demonstrated a 
significant PFS advantage (median 10.1 vs. 4.4 months) with Osimertinib treatment compared to platinum-pemetrexed combination chemotherapy. Objective response rate (ORR) was achieved in $71 \%$ of the patients who received Osimertinib. Median overall survival (OS) was 26.8 months with Osimertinib, however, the updated analysis did not show a significant OS benefit, mainly secondary to a remarkable cross-over rate (67\% of the patients in the chemotherapy group) to Osimertinib arm (7). Osimertinib became the standard of care for second-line treatment of T790M-mutant advanced NSCLC patients whose disease progressed after first-line EGFR-TKI therapy, based on the results of the AURA3 trial(2).

Recently, Osimertinib achieved a longer OS compared to first-generation EGFR-TKIs (median 38.6 vs. 31.8 months) in the treatment-naive advanced NSCLC population with exon 19 deletions and L858R mutations (8). However, there are many patients who have not progressed under first-line treatment with first or second-generation TKIs. Furthermore, Osimertinib may not be accessible because of many reasons related to approval policy, reimbursement issues, insurance coverage, etc., in the first-line treatment for many patients worldwide, as well as in our country. This status emphasizes the importance of sequential strategy and second-line efficacy.

Randomized phase 3 trials are the most important tools to assess the efficacy and safety of a new treatment agent or strategy. These studies may have strict inclusion and exclusion criteria which usually under represents patients with poor performance and elderly. They also have close follow-up and monitorization rules, and a tendency to over or underestimate some factors regarding efficacy and safety profile, some of which may not be clinically so meaningful. Studies which evaluated the outcomes of real-life patients who received the treatment agent may help to close this gap.

In this multicenter study, we aimed to determine the real-life efficacy and safety of Osimertinib in pretreated advanced NSCLC patients with T790M mutation, in Turkey.

\section{Materials And Methods}

This multicenter, retrospective trial included pathologically and radiologically confirmed T790M-mutant, pretreated, advanced NSCLC patients who received Osimertinib between January 2016 and January 2021. There were only six patients who received Osimertinib in first-line treatment regardless of the T790M mutation.

The study was performed in 24 different centers in Turkey with collaboration of the Turkish Oncology Group. Data were obtained from patients' files and electronic databases of the hospitals. The EGFR and/or T790M mutation was analyzed either in the tumor tissue sample or in plasma circulating tumor DNA (ctDNA) by local laboratories of each center.

Primary endpoint was time-to-treatment discontinuation (TTD) and calculated from the date of the initiation of Osimertinib treatment to discontinuation of the drug or death. Secondary endpoints were OS, response rate according to the criteria of RECIST version 1.1 by the investigator, and safety. OS was defined as the time from initiation of Osimertinib to death from any cause. Adverse events were assessed 
by using the National Cancer Institute Common Terminology Criteria for Adverse Events (NCI CTCAE), version 4.0.

All statistical procedures were performed with SPSS 22.0 (SPSS Inc, Chicago, Illinois). The variables were investigated using visual (histogram, probability plots) and analytic methods (KolmogorovSmirnov/Shapiro-Wilk's test) to determine whether or not they are normally distributed. Categorical variables were compared using the Chi-square or Fisher's exact test, where appropriate. Differences in continuous values between the two groups were assessed with Student's $t$-test for normally distributed variables and non-parametric Mann-Whitney $U$ tests for non-normally distributed variables as appropriate. In normally distributed parameters, the correlation coefficients and their significance were calculated using the Pearson test and in non-normally or ordinal variables, the correlation coefficients and their significance were calculated using the Spearman test. Survival curves were obtained by the KaplanMeier method, and the log-rank test was used to compare survival differences. A $P$ value $<0.05$ was considered to statistically significant. A 5\% type-1 error level was used to infer statistical significance.

Local Clinical Research Ethics Committee's approval was obtained.

\section{Results}

\section{Patient Characteristics}

Median age of 163 patients at the time of diagnosis was 57 (min-max: 26-79), and it did not significantly differ between male and female. The $59.5 \%$ of the patients were female. Approximately all of the patients had adenocarcinoma (98.1\%) histology. EGFR exon 19 del mutation were seen in $68.7 \%$ of the patients. Of 163 patients with advanced disease, $153(93.9 \%)$ had metastatic disease. There were 49 patients $(30.1 \%)$ who had brain metastasis. Demographic and clinical features of the patients are summarized in Table 1. 
Table 1

Demographic and Clinical Characteristics of the Patients

\begin{tabular}{|c|c|c|c|}
\hline Feature & $\%, n$ & Feature & $\%, n$ \\
\hline Sex & $59.5 \%, n=97$ & ECOG Performance & $23.3 \%, n=38$ \\
\hline Female & $(58,29-79)$ & 0 & $52.8 \%, \mathrm{n}=86$ \\
\hline (median age, min-max) & $40.5 \%, n=66$ & 1 & $11.7 \%, \mathrm{n}=19$ \\
\hline Male & $(56,26-79)$ & $\geq 2$ & $12.3 \%, n=20$ \\
\hline (median age, min-max) & & NA & \\
\hline Tumor Histology & $98.1 \%, n=160$ & Smoking Status & $69.3 \%, n=113$ \\
\hline Adenocarcinoma & $<1 \%, \mathrm{n}=1$ & Non-Smoker & $24.5 \%, \mathrm{n}=41$ \\
\hline Squamous cell & $1.2 \%, n=2$ & Previous exposure & $5.5 \%, n=9$ \\
\hline NOS & & Active smoker & \\
\hline Metastatic Site & $75.5 \%, n=123$ & No. of Previous Regimens & $3.7 \%, n=6$ \\
\hline Lung & $59.5 \%, n=97$ & 0 & $58.9 \%, \mathrm{n}=96$ \\
\hline Bone & $41.7 \%, n=68$ & 1 & $29.4 \%, n=48$ \\
\hline Pleura & $30.1 \%, n=49$ & 2 & $5.5 \%, n=9$ \\
\hline Brain & $19.6 \%, n=32$ & 3 & $2.4 \%, n=4$ \\
\hline Liver & & $\geq 4$ & \\
\hline Type of EGFR Mutation & $96.3 \%, n=157$ & Previous TKi & $79.8 \%, n=130$ \\
\hline T790M & $68.7 \%, n=112$ & Erlotinib & $6.1 \%, n=10$ \\
\hline Exon 19 deletion & $22.7 \%, n=37$ & Gefitinib & $6.7 \%, n=11$ \\
\hline Exon $21 \mathrm{~L} 858 \mathrm{R}$ & $3.7 \%, n=6$ & Afatinib & $3.7 \%, n=6$ \\
\hline Other & & NA & \\
\hline
\end{tabular}

There was no significant difference in terms of EGFR mutation subtype between female and male patients. Non-smokers were significantly more frequent $(p<0.05)$ in female patient group $(85.6 \%, n=83)$ compared to males $(45.5 \%, \mathrm{n}=30)$.

\section{Previous Anticancer Treatments}

There were only 6 patients who received Osimertinib as first-line treatment regardless of T790M mutation. All other patients $(n=157)$ had T790M mutation. There were 96 patients $(58.9 \%)$ who received Osimertinib as second-line and 48 patients (29.4\%) as $\geq$ third-line treatment. Among 151 patients who received first- or second-generation EGFR-TKI before Osimertinib, Erlotinib was given to $86 \%(n=130)$, while $6.6 \%(n=10)$ got Gefitinib and 7.2\% $(n=11)$ got Afatinib. Median duration of exposure to previous 
TKI treatment was calculated as 16 months (min-max: 1-85 months), irrespective of the agent that used or disease status (Table 1).

\section{Efficacy and Safety Outcomes of Osimertinib}

After median follow-up of 13 months (min-max:1.1-52.2 months), response assessment obtained from 161 patients. Complete response (CR) was achieved in 11 patients $(6.7 \%)$ and ORR was $82.2 \%$ with Osimertinib treatment. There were only 6 patients $(3.7 \%)$ whose best response to treatment was progressive disease (PD) (Table 2).

Table 2

\begin{tabular}{|c|c|}
\hline Treatment Response & $\%, n$ \\
\hline Complete Response (CR) & $6.7 \%, n=11$ \\
\hline Partial Response (PR) & $75.5 \%, n=123$ \\
\hline Objective Response Rate (ORR) & $82.2 \%, n=134$ \\
\hline Stable Disease (SD) & $12.9 \%, n=21$ \\
\hline Disease Control Rate (DCR) & $95 \%, n=155$ \\
\hline Progressive Disease (PD) & $3.7 \%, n=6$ \\
\hline
\end{tabular}

Seventy-five events occurred in terms of TTD and median TTD with Osimertinib treatment was 21.6 months ( $95 \% \mathrm{Cl}, 17.4$ to 25.7 months) (Fig. 1). In the pretreated population ( $n=157)$, median TTD was also 21.6 months ( $95 \% \mathrm{Cl}, 17.4$ to 25.8 months).

In patient subgroup $(\mathrm{n}=96)$ that received Osimertinib as second-line treatment, median TTD was 22.7 months ( $95 \% \mathrm{Cl}, 14.7$ to 30.7 months). Similarly, patients $(n=61)$ who received Osimertinib as third-line or later achieved a median TTD of 21.6 months ( $95 \% \mathrm{Cl}, 17.1$ to 26 months).

There was a significant TTD difference between patient groups with exon 19 del $(n=112)$ and with exon 21, L858R mutation ( $\mathrm{n}=37$ ). Median TTD was 25.3 months $(95 \% \mathrm{Cl}, 21.1$ to 29.5 months) vs. 15.1 months ( $95 \% \mathrm{Cl}, 5.4$ to 24.9 months) in patients with 19 del and L858R mutation, respectively $(p=0.045)$. Also, a significant TTD difference was demonstrated between gender, in favor of female patients with a median of 24 vs. 15.1 months ( $p=0.021)$. TTD was significantly shorter in patients with brain metastasis compared to without brain metastasis (median of 11.4 vs 24 months, respectively, $p=0.045$ ) (Table 3 ). There were no significant TTD differences in terms of smoking status, ECOG performance status, presence, or grade of any side effects. 
Table 3

Time to Treatment Discontinuation and Overall Survival in Patient Subgroups

\begin{tabular}{|c|c|c|}
\hline Patient Subgroups ( $\mathrm{n}$ of Events / $\mathrm{n}$ ) & TTD months (median, $95 \% \mathrm{Cl}$ range) & $\mathbf{p}$ \\
\hline Age < $65(57 / 124)$ & $21.6(17.5-25.6)$ & 0.63 \\
\hline Age $\geq 65(18 / 39)$ & $19.2(8.3-30.1)$ & \\
\hline Female (39/97) & $24(19.6-28.4)$ & 0.021 \\
\hline Male $(36 / 66)$ & $15.1(7.6-22.6)$ & \\
\hline Nonsmoker (49/113) & $21.6(17.3-25.9)$ & 0.13 \\
\hline Smoking History $(26 / 50)$ & $16(3-28.9)$ & \\
\hline 2nd Line Osimertinib (40/96) & $22.7(14.7-30.7)$ & 0.81 \\
\hline$\geq$ 3rd Line Osimertinib $(33 / 61)$ & $21.6(17.1-26)$ & \\
\hline Exon 19 deletion (50/112) & $25.3(21.1-29.5)$ & 0.045 \\
\hline Exon 21 L858R (20/37) & $15.1(5.4-24.9)$ & \\
\hline Brain Metastasis (-) (49/114) & $24(19.4-28.6)$ & 0.045 \\
\hline Brain Metastasis (+) $(26 / 49)$ & $11.4(6.2-16.7)$ & \\
\hline Patient Subgroups ( $\mathrm{n}$ of Events / n) & OS months (median, $95 \% \mathrm{Cl}$ range) & $\mathbf{p}$ \\
\hline Age < $65(37 / 124)$ & $35.5(23.8-47.1)$ & 0.18 \\
\hline Age $\geq 65(14 / 39)$ & $32.1(22.1-42.2)$ & \\
\hline Female (26/97) & $35.5(22.1-48.8)$ & 0.063 \\
\hline Male $(25 / 66)$ & $24.2(14.5-34)$ & \\
\hline Nonsmoker (31/113) & $35.5(21.4-49.5)$ & 0.038 \\
\hline Smoking History $(20 / 50)$ & $27.7(15.9-39.4)$ & \\
\hline 2nd Line Osimertinib (29/96) & $27.7(22.7-32.7)$ & 0.35 \\
\hline$\geq$ 3rd Line Osimertinib $(20 / 61)$ & $32.1(19-45.3)$ & \\
\hline Exon 19 deletion (32/112) & $32.1(26.5-37.8)$ & 0.075 \\
\hline Exon 21 L858R (15/37) & $20.1(18.1-22.2)$ & \\
\hline Brain Metastasis (-) (31/114) & $32.1(26.5-37.8)$ & 0.021 \\
\hline Brain Metastasis (+) $(20 / 49)$ & $17.3(13.9-20.7)$ & \\
\hline
\end{tabular}

A total of 51 patients (31.2\%) died. Estimated median OS was calculated as 32.1 months $(95 \% \mathrm{Cl}, 22.1$ to 42.2 months) (Fig. 2). As expected, patients with brain metastasis had significantly shorter OS compared with patients who had no brain metastasis (median OS of 17.3 vs. 32.1 months, respectively, $p=0.021$ ). 
There was a trend in OS in favor of female gender, and exon 19 del mutation compared with L858R, but these differences have failed to reach statistical significance (Table 3).

The tolerability and safety of Osimertinib were assessed. At least one side effect reported in $51.5 \%(n=$ $84)$ of the patients. Rate of grade 3 or 4 side effects was $11.7 \%(n=19)$. Most common side effects were fatigue (33.1\%), decreased appetite (32.5\%), skin toxicity (28.8\%), diarrhea (17.2\%), and paronychia (12.9\%). Grade 3 pneumonitis was seen only in one patient. None of the patients experienced an adverse event leading to death or permanent discontinuation of the drug. Drug dose was reduced in 9 patients (5.5\%), and treatment was interrupted temporarily in 9 patients.

\section{Discussion}

In this real-life study, as a primary endpoint; Osimertinib demonstrated a quite impressive TTD with a median of 21.6 months, in pretreated advanced EGFR-mutant NSCLC patients. Secondary endpoints were also consistent with $82.2 \%$ of ORR, and estimated-median OS of 32.1 months, with a favorable safety profile.

AURA3 was an international, phase 3 study that randomized 419 patients with T790M-mutant advanced NSCLC to second-line Osimertinib or chemotherapy arms (6). The study reported a median of 10.1 months PFS with Osimertinib treatment. Demographic and clinical features of the patient population were similar in terms of age (62 and 57), sex (female, $62 \%$ and 59\%), rate of CNS involvement (33\% and $30 \%$ ), and EGFR mutation subtypes (exon 19 del, 68\% and 68\%) in AURA3 and our study, respectively (6). However, in the Osimertinib arm of the AURA3 study, $65 \%$ of the patients were Asian, $83 \%$ of the patients had adenocarcinoma histology (in our study it was $98 \%$ ), $96 \%$ had only one-line of previous treatment (in our study it was 59\%) (6). Moreover, our study group had received more previous treatment lines before Osimertinib.

In this context, the survival outcomes of other real-life studies varied between median 9.4 and 14.5 months of PFS, in the second-line treatment of advanced NSCLC with T790M mutation (9-14). The Spanish Lung Cancer Group reported a median of 9.4 months PFS in 155 patients, and this was a very close to the PFS reported in the pivotal phase 3 trial $(6,10)$. Other studies from different regions and ethnicities like China, Japan, France, and Poland demonstrated slightly better real-life outcomes than the AURA3 trial with approximately median $11-14$ months of PFS $(9,11-14)$. In general, outcomes of reallife experiences with the different classes of drugs just like cytotoxic chemotherapy, barely exceed the success of pivotal studies. Because patients often have more comorbidities and worse performance status than patient population strictly selected in phase 3 studies. However, targeted agents typically could demonstrate similar or better results in several studies. Clinicians' increasing experience in the management of treatment side effects and sustainable clinical benefit observed in some patient groups might contribute to these results.

Median 21.6 months of TTD in our study was a quite different outcome than the PFS results of phase 3 AURA3 or other real-life studies. Of course, these two different end-points did not refer to the same 
situation, and they could not be compared directly in any clinical scenario. Indeed, our aim mostly emphasizes the distinct features of the TTD and PFS as study end-points. Unlike other studies, TTD did not identify the disease progression as "an event" according to RECIST criteria, and includes patient subgroups in which clinicians decided to continue the treatment post-progression.

Importance of TTD was demonstrated in a recent study that analyzed 18 different randomized studies with 8947 NSCLC patients (15). Five of these 18 studies included 1151 patients who received targeted TKI therapy for EGFR-mutant NSCLC. Median TTD exceeded median PFS by 2 months (13.4 versus 11.4 months) in this subgroup. Also, the rate of "late TTD" (identified as TTD - PFS $\geq 3$ months) was $12.4 \%$ in EGFR-mutant patients and this rate was higher than chemotherapy and immunotherapy studies (15). Another study from Spain which included 91 patients who received post-progression treatment after second or third-line Osimertinib therapy for T790M mutation-positive disease, reported a median of 6.4 months post-progression PFS with Osimertinib treatment in 50 (54\%) patients (16). Both post-progression PFS and OS were significantly longer in the post-progression Osimertinib arm compared with other treatments in this study (16).

The other determinant that might improve the TTD could be inclusion of local ablative therapies (LAT) to patient care. As one of the weaknesses of our study, our database did not include the percentages of patients who received LAT. However, it is a routine part of daily clinical practice especially for patients whose disease showed oligoprogression and/or isolated CNS progression (17). A recent study by Zeng et al., included 108 patients ( $n=83$ for the second-line Osimertinib) who had oligo-residual disease $(\leq 5$ metastatic lesions) and treated with Osimertinib, demonstrated a PFS advantage in patients $(n=14)$ who had received LAT compared with others (NR vs 12.8 months, $p=0.01$ ) (18). In this small patient subgroup ( $n=8$ for first-line Osimertinib, and $n=6$ second-line Osimertinib) in which administered LAT to their Osimertinib treatment, 3-year PFS rate was reported as $54.5 \%$ (18).

Main reasons of choosing TTD as our primary end-point were also the weaknesses of our study. TTD was more suitable for a retrospective study that did not perform a central assessment of treatment response and included many centers around the country which may have different clinical approaches and LAT practices. But at the same time, it might reflect directly the sustainable and real-life beneficial effects of treatment to allow the post-progression continuation and other interventions to the treatment process. Clinicians' choice to hold on to the drug throughout median 21.6 months was quite understandable in this very special patient subgroup who did not have too many treatment options after Osimertinib treatment, rather than chemotherapy which has highly suspicious efficacy in third or later-lines.

TTD was significantly longer in favor of women, patients with Exon 19 deletion, and patients without brain metastasis compared to men, Exon 21 L858R mutation, and patients with brain metastasis, respectively. There was greater risk reduction observed in female gender and patients with Exon 19 del mutation, with both first-line and second-line Osimertinib treatment, in pivotal phase 3 studies $(6,19)$. Also, our results were compatible with a recent meta-analysis by Lee et al. that demonstrated $50 \%$ greater benefit in Exon 19 del mutation than Exon 21 L858R mutation $(p<0.01)$, and 27\% greater benefit in 
women than men $(p=0.02)$ with first or second-generation EGFR-TKIs compared with chemotherapy (20). Real-life studies from Poland and France also reported significant PFS advantage in patients with Exon 19 del mutation $(11,12)$.

Brain metastasis is a worse prognostic factor for NSCLC and drug penetrance to CNS remains a problem even for highly effective therapies like Osimertinib (21). TTD in patients with brain metastasis is significantly shorter than patients without brain metastasis, however, median 11.4 months of TTD was similar to the AURA3 trial's 8.5 months of PFS (6). In our study, patients with asymptomatic brain metastasis might be under-represent in our brain metastatic subgroup because of the lack of periodic brain MRI screening in daily clinical practice.

In the pivotal phase 3 trial, $71 \%$ of the patients achieved ORR and 93\% DCR with Osimertinib (6). In our study, ORR was higher (82\%) and DCR was similar with 95\%. Studies from Europe already reported lower rates with approximately $40-50 \%$ of ORR $(10,12)$. No data was indicating that the Turkish population might be more "sensitive" to this treatment than Western population. Our study did not perform a central assessment for radiological review, and patient-selection bias always has to be taken into consideration as a possible determinant of a retrospective study.

After median 13 months follow-up, estimated median OS was 32.1 months (median 27.7 months for second-line and 32.1 months for $\geq 3$-lines of treatment). Median OS of the Osimertinib arm in AURA3 trial was 26.8 months (7). Real-life results showed a median OS of 20 months in the western population and 24 months in the Asian population $(11,14)$. In a phase 2 study, 3-year OS rate was $54 \%$ in Japanese patients (22). In another study, median OS from the failure of first-line EGFR-TKI was reported as 42.6 months in patients who had T790M mutation with a history of Osimertinib use (23). Relatively short follow-up period, risk of patient-selection bias, and also possible differences in the sequential therapies might have affected our OS results.

Safety profile was favorable with only $5.5 \%$ of temporary drug interruption. Most common side effects were similar with recent data. Rates of any adverse events and grade 3-4 adverse events were lower than the AURA3 study (6). Clinicians' tendency to underestimate the side effects -especially grade 1 and 2which will not influence treatment strategy, might be a possible reason in daily clinical practice. For example, grade 1-2 pneumonitis was seen in 9 of 279 patients in AURA3 however it was none in our study. Probably, asymptomatic grade 1 events might be underestimated and the symptoms of grade 2 events might be explained with other clinical entities. But grade $\geq 3$ pneumonitis was seen in one patient in both studies (6).

In conclusion, Osimertinib is a highly effective therapy in second-line treatment of NSCLC patients with T790M mutation, with a favorable safety profile.

\section{Declarations}

Funding: No role for any funding source. 
Conflicts of Interest: The authors declare no conflicts of interes

\section{References}

1. Bray F, Ferlay J, Soerjomataram I, Siegel RL, Torre LA, Jemal A (2018) Global cancer statistics 2018: GLOBOCAN estimates of incidence and mortality worldwide for 36 cancers in 185 countries. CA Cancer J Clin 68(6):394-424

2. Yuan M, Huang L-L, Chen J-H, Wu J, Xu Q (2019) The emerging treatment landscape of targeted therapy in non-small-cell lung cancer. Signal Transduction Targeted Therapy 4(1):61

3. Zhang Y-L, Yuan J-Q, Wang K-F, Fu X-H, Han X-R, Threapleton D et al (2016) The prevalence of EGFR mutation in patients with non-small cell lung cancer: a systematic review and meta-analysis. Oncotarget 7(48):78985-78993

4. Ricciuti B, Baglivo S, Paglialunga L, De Giglio A, Bellezza G, Chiari R et al (2017) Osimertinib in patients with advanced epidermal growth factor receptor T790M mutation-positive non-small cell lung cancer: rationale, evidence and place in therapy. Ther Adv Med Oncol 9(6):387-404

5. Yu HA, Arcila ME, Rekhtman N, Sima CS, Zakowski MF, Pao W et al (2013) Analysis of tumor specimens at the time of acquired resistance to EGFR-TKI therapy in 155 patients with EGFR-mutant lung cancers. Clin Cancer Res 19(8):2240-2247

6. Mok TS, Wu YL, Ahn MJ, Garassino MC, Kim HR, Ramalingam SS et al (2017) Osimertinib or Platinum-Pemetrexed in EGFR T790M-Positive Lung Cancer. N Engl J Med 376(7):629-640

7. Wu YL, Mok TSK, Han JY, Ahn MJ, Delmonte A, Ramalingam SS et al (2019) Overall survival (OS) from the AURA3 phase III study: Osimertinib vs platinum-pemetrexed (plt-pem) in patients (pts) with EGFR T790M advanced non-small cell lung cancer (NSCLC) and progression on a prior EGFRtyrosine kinase inhibitor (TKI). Ann Oncol 30:ix158

8. Ramalingam SS, Vansteenkiste J, Planchard D, Cho BC, Gray JE, Ohe Y et al (2019) Overall Survival with Osimertinib in Untreated, EGFR-Mutated Advanced NSCLC. N Engl J Med 382(1):41-50

9. Peng D, Shan D, Dai C, Li J, Wang Z, Huang Z et al (2021) Real-World Data on Osimertinib in Chinese Patients with Pretreated, EGFR T790M Mutation Positive, Advanced Non-Small Cell Lung Cancer: A Retrospective Study. Cancer Manag Res 13:2033-2039

10. Provencio M, Terrasa J, Garrido P, Campelo RG, Aparisi F, Diz P et al (2021) Osimertinib in advanced EGFR-T790M mutation-positive non-small cell lung cancer patients treated within the Special Use Medication Program in Spain: OSIREX-Spanish Lung Cancer Group. BMC Cancer 21(1):230

11. Auliac JB, Pérol M, Planchard D, Monnet I, Wislez M, Doubre H et al (2019) Real-life efficacy of osimertinib in pretreated patients with advanced non-small cell lung cancer harboring EGFR T790M mutation. Lung Cancer 127:96-102

12. Knetki-Wróblewska M, Kowalski DM, Czyżewicz G, Bryl M, Wrona A, Dziadziuszko R et al (2020) Effectiveness of osimertinib in patients with lung adenocarcinoma in clinical practice - the Expanded Drug Access Program in Poland. Advances in Respiratory Medicine 88(3):189-196 
13. Ohe Y, Kato T, Sakai F, Kusumoto M, Endo M, Saito Y et al (2020) Real-world use of osimertinib for epidermal growth factor receptor T790M-positive non-small cell lung cancer in Japan. Jpn J Clin Oncol 50(8):909-919

14. Kishikawa T, Kasai T, Okada M, Nakachi I, Soda S, Arai R et al (2020) Osimertinib, a third-generation EGFR tyrosine kinase inhibitor: A retrospective multicenter study of its real-world efficacy and safety in advanced/recurrent non-small cell lung carcinoma. Thoracic Cancer 11(4):935-942

15. Blumenthal GM, Gong Y, Kehl K, Mishra-Kalyani P, Goldberg KB, Khozin S et al (2019) Analysis of time-to-treatment discontinuation of targeted therapy, immunotherapy, and chemotherapy in clinical trials of patients with non-small-cell lung cancer. Ann Oncol 30(5):830-838

16. Cortellini A, Leonetti A, Catino A, Pizzutillo P, Ricciuti B, De Giglio A et al (2020) Osimertinib beyond disease progression in T790M EGFR-positive NSCLC patients: a multicenter study of clinicians' attitudes. Clin Transl Oncol 22(6):844-851

17. Kim C, Roper N, Hoang CD, Szabo E, Connolly M, Padiernos E et al (2017) Local ablative therapy (LAT) for oligoprogressive, EGFR-mutant, non-small cell lung cancer (NSCLC) after treatment with osimertinib. J Clin Oncol 35(15_suppl):e20545-e

18. Zeng Y, Ni J, Yu F, Zhou Y, Zhao Y, Li S et al (2020) The value of local consolidative therapy in Osimertinib-treated non-small cell lung cancer with oligo-residual disease. Radiat Oncol 15(1):207

19. Soria J-C, Ohe Y, Vansteenkiste J, Reungwetwattana T, Chewaskulyong B, Lee KH et al (2017) Osimertinib in Untreated EGFR-Mutated Advanced Non-Small-Cell Lung Cancer. N Engl J Med 378(2):113-125

20. Lee CK, Wu Y-L, Ding PN, Lord SJ, Inoue A, Zhou C et al (2015) Impact of Specific Epidermal Growth Factor Receptor (EGFR) Mutations and Clinical Characteristics on Outcomes After Treatment With EGFR Tyrosine Kinase Inhibitors Versus Chemotherapy in EGFR-Mutant Lung Cancer: A MetaAnalysis. J Clin Oncol 33(17):1958-1965

21. Ballard P, Yates JW, Yang Z, Kim DW, Yang JC, Cantarini M et al (2016) Preclinical Comparison of Osimertinib with Other EGFR-TKIs in EGFR-Mutant NSCLC Brain Metastases Models, and Early Evidence of Clinical Brain Metastases Activity. Clin Cancer Res 22(20):5130-5140

22. Hirashima T, Satouchi M, Hida T, Nishio M, Kato T, Sakai H et al (2019) Osimertinib for Japanese patients with T790M-positive advanced non-small-cell lung cancer: A pooled subgroup analysis. Cancer Sci 110(9):2884-2893

23. Chiang CL, Huang HC, Shen Cl, Luo YH, Chen YM, Chiu CH (2020) Post-Progression Survival in Secondary EGFR T790M-Mutated Non-Small-Cell Lung Cancer Patients With and Without Osimertinib After Failure of a Previous EGFR TKI. Target Oncol 15(4):503-512

\section{Figures}




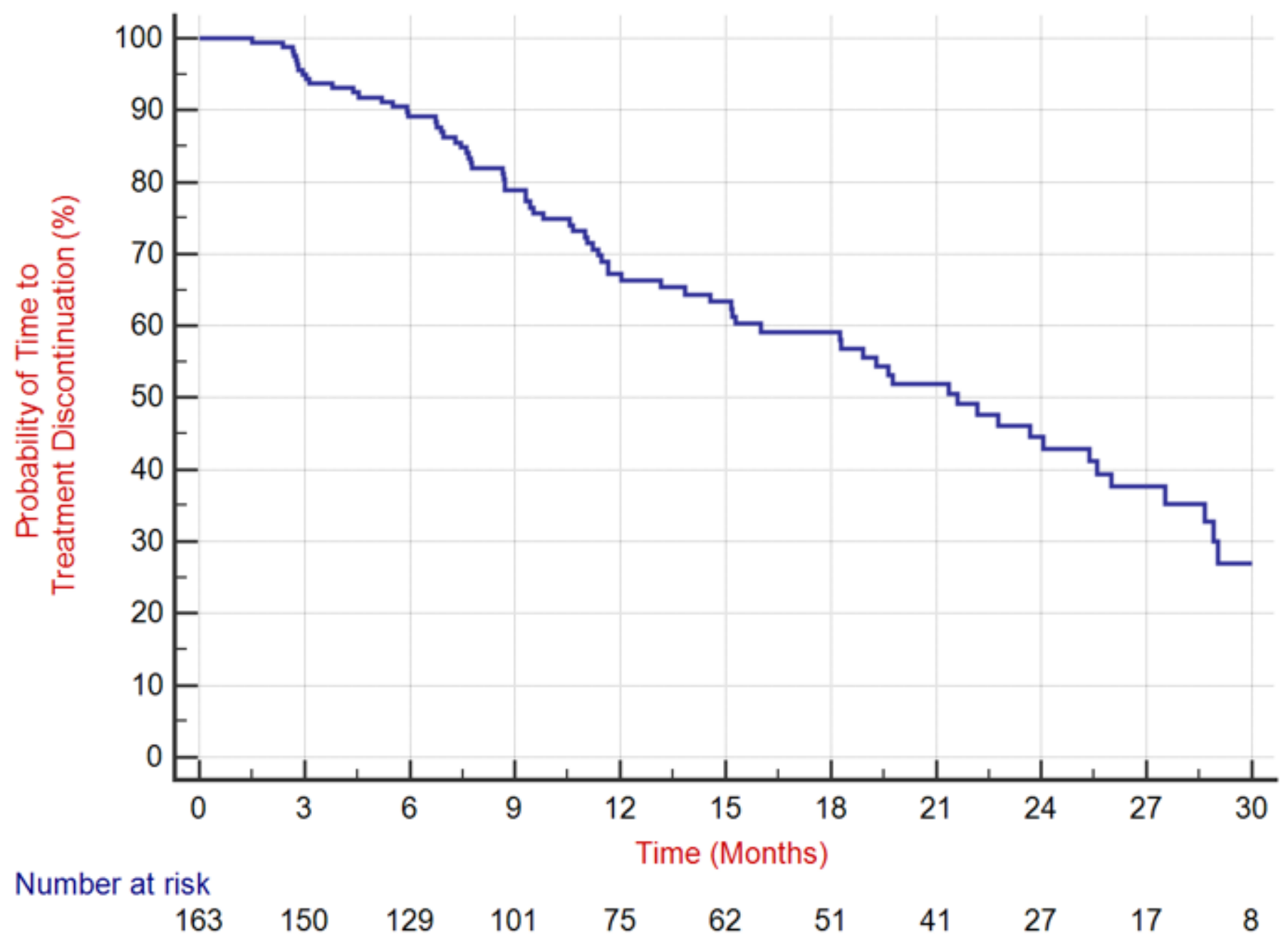

Figure 1

Time to Treatment Discontinuation with Osimertinib Treatment 


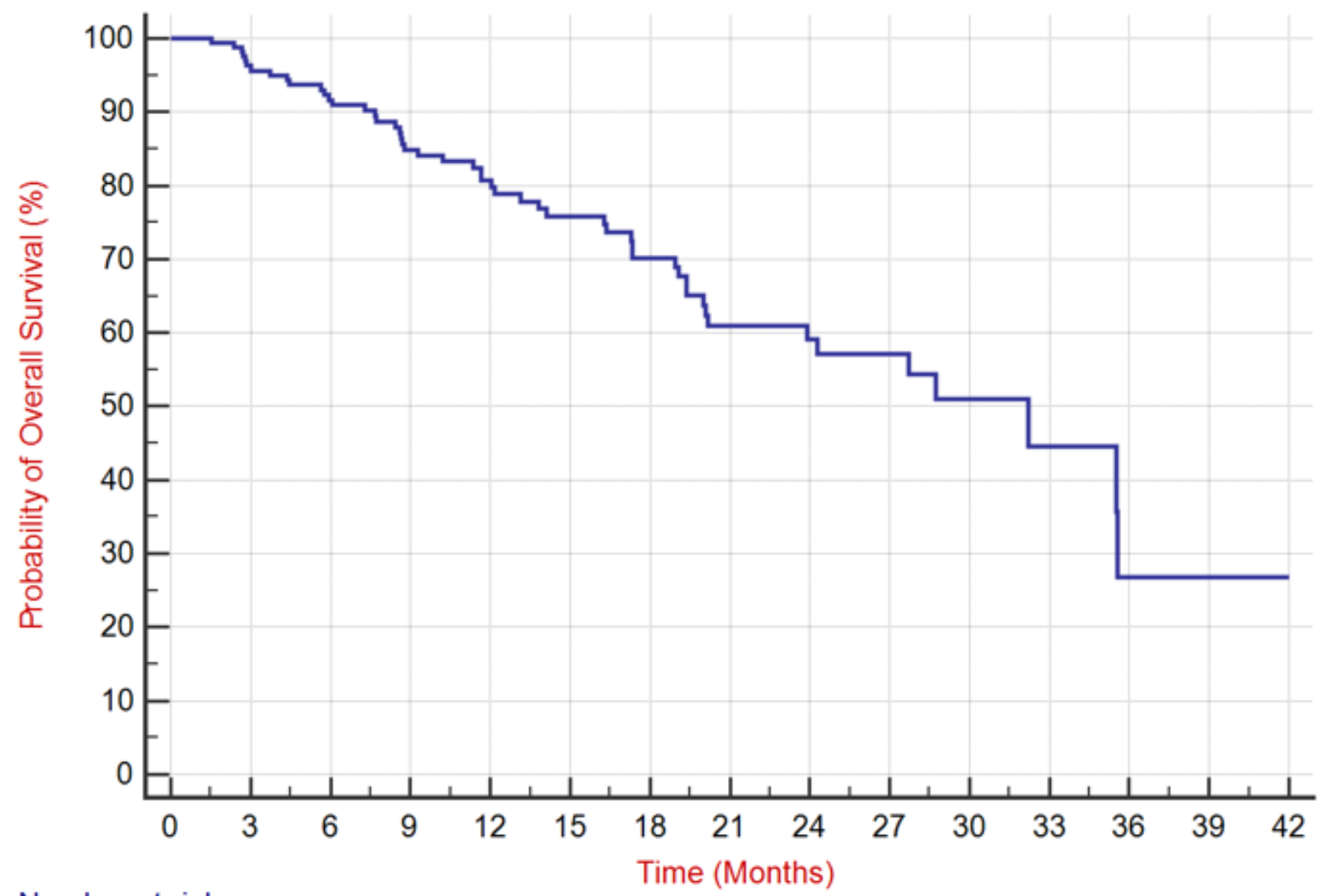

Number at risk

$\begin{array}{lllllllllllllll}163 & 152 & 132 & 108 & 88 & 73 & 58 & 45 & 31 & 22 & 11 & 7 & 3 & 2 & 2\end{array}$

Figure 2

Overall Survival with Osimertinib Treatment 